\title{
Pronounced antitumor effect of LAK-like cells induced in the peritoneal cavity of mice after intraperitoneal injection of OK-432, a killed Streptococcal preparation
}

\author{
Motoo Saito $^{1}$, Osamu Ichimura ${ }^{1}$, Motoyuki Kataoka ${ }^{1}$, Yoichiro Moriya ${ }^{1}$, Kouko Ueno ${ }^{1}$, Yutaka Sugawara ${ }^{1}$, Masaki Nanjo ${ }^{2}$, \\ and Nakao Ishida ${ }^{2}$ \\ Research Laboratories, Chugai Pharmaceutical Co., Ltd., 3-41-8 Takada, Toshima-ku, Tokyo 171, and \\ ${ }^{2}$ Department of Bacteriology, Tohoku University School of Medicine, 2-1 Seiryo-machi, Sendai 980, Japan
}

\begin{abstract}
Summary. More than $80 \%$ of $\mathrm{BALB} / \mathrm{c}$ mice bearing BAMC- 1 ascites tumor were completely cured after five consecutive (once every 2 days) i. p. injections of a $0.1 \mathrm{mg}$ dose of OK-432, beginning on day 2 after tumor implantation. The antitumor effect of OK-432 was abolished in athymic nu/nu mice and in anti-thymocyte globulin-treated euthymic BALB/c mice, so although OK-432 treatment did increase the length of survival, all animals eventually died as a result of tumor growth. When peritoneal exudate cells (PEC), obtained on day 12 from OK-432-treated BAMC-1-bearing euthymic mice were evaluated for in vivo tumor neutralization activity, all mice receiving an i. p. injection of the admixture of the nonadherent PEC $\left(1 \times 10^{7}\right.$ cells) with BAMC-1 cells $\left(1 \times 10^{5}\right)$ survived for more than 60 days. When the same nonadherent PEC $\left(1 \times 10^{7}\right.$ cells $)$ were i. p. transferred adoptively 1 day after the inoculation of $1 \times 10^{5}$ BAMC-1 tumor cells, again all mice survived.

When these in vivo active PEC were tested for cytotoxicity in vitro against fresh BAMC-1 tumor cells, natural killer (NK) sensitive syngeneic RL $0^{*} 1$, NK-sensitive allogeneic YAC-1 cells, NK-resistant syngeneic Meth-A cells, allogeneic tumor cells (EL4, B16, and P815) and xenogenic human cells, the PEC were found to be capable of lysing BAMC-1 tumor cells together with almost all of the other tumor cells, including NK-resistant cells. Nonadherent PEC contained at least two subpopulations of killer cells. One, directed to syngeneic BAMC-1 cells, was both Thy 1.2 and asialo GM1 positive, and another, directed to allogeneic YAC-1 cells, was asialo GM1 positive but Thy 1.2 negative. A cold target inhibition assay also suggested the presence of more than two subpopulations.

These results indicate that $T$ cells play a determined role in the immunotherapeutic effect of OK-432 on $\mathrm{BALB} / \mathrm{c}$ mice bearing BAMC-1 tumor, although the participation of activated macrophages could not be excluded. The cells responsible for killing BAMC- 1 and other tumor cells appearing in the PEC on day 12 were characterized as containing at least two kinds of lymphokine-activated killer cells.
\end{abstract}

\section{Introduction}

A bacterial immunopotentiator OK-432, a killed Streptococcus preparation, has been extensively used as a thera-

Offprint requests to: $\mathrm{M}$. Saito peutic agent for malignant diseases in humans [26, 27, 31] and experimental animals $[7,21,32]$ and has produced a number of successful results.

Early studies indicated that one possible cause of the antitumor effect of OK-432 is due to its direct action on tumor cells, inhibiting both RNA and DNA synthesis [14]. Another is its host-mediated action, and early studies characterized OK-432 as a potent interferon gamma (IFN $\gamma$ ) inducer $[18,19]$ along with bacille Calmette-Guénin and Corynebacterium parvum. Further studies disclosed its ability to induce interleukin 1 (IL-1) and interleukin 2 (IL-2) [8]. In concordance with these findings, $\mathrm{OK}-432$ has also been shown to augment natural killer (NK) activity in humans and mice $[15,28,29]$, to induce cytotoxic macrophages [9, 20], and to activate cytotoxic polymorphonuclear leukocytes after in vivo administration [30]. OK-432 has also been known to induce cytotoxic $\mathrm{T}$ lymphocytes in the peritoneal cavity of $\mathrm{BC}-47$ solid tumor-bearing rats when injected i. p. [7]. These enhancements have been attributed to OK-432-induced IFN $\gamma[6,19,22]$. According to the macrophage- $T$ cell lymphokine cascade reaction theory [3], the participation of IL-1, IL-2, and IFN $\gamma$ are a prerequisite to the appearance of cytotoxic T lymphocytes (CTL) [4], which are believed to mediate the direct destruction of tumor cells in vivo [2, 5, 25]. So far, however, little is known about the generation or infiltration of syngeneic CTL at the tumor site after OK-432 treatment.

The purpose of this study was to characterize the effector cells responsible for the significant antitumor effect of OK-432 in vivo. To accomplish this, in vivo effector cells were assessed by both Winn's neutralization assay and adoptive transfer to tumor-bearing mice. Next, an in vitro cell marker analysis was conducted with in vivo effector cell populations by a chromium release cytotoxic assay with a variety of target cells.

\section{Materials and methods}

Mice and tumor cell lines. Female, pathogen free BALB/c mice, 6-8 weeks old, and female littermates nu/nu and $\mathrm{nu} /+\mathrm{BALB} / \mathrm{c}$ mice, 7 weeks old, were purchased from Charles River Japan and Clea Japan (Tokyo). BAMC-1, methylcholanthrene-induced fibrosarcoma in BALB/c mice, was established in our laboratory and maintained in ascitic form by a weekly passage in syngeneic mice. The i. p. lethal dose of BAMC-1 was $10^{3}$ cells/mouse. Other target cells used for the in vitro cytotoxicity test were syn- 
geneic (Meth-A and RL $0^{\circ}$ ), allogeneic (EL4, B16, P815 and YAC-1), and xenogenic human cells (K562, T24, PLC, and KATO3) of different NK sensitivity. These were maintained in RPMI-1640 medium (GIBCO, Grand Island, NY) supplemented with $10 \%$ heat-inactivated fetal bovine serum (FBS, gibco) and $60 \mu \mathrm{g} / \mathrm{ml} \mathrm{kanamycin} \mathrm{(Mei-}$ ji Seika Co., Ltd., Tokyo,).

Therapeutic effect of $O K-432$ against BAMC-1 tumor. A lyophilized preparation of OK-432 (Chugai Pharmaceutical Co., Ltd., Tokyo) was suspended in a saline solution at a concentration of $1 \mathrm{mg} / \mathrm{ml}$ and $0.1 \mathrm{ml} \mathrm{i.p}$. injections were made on days $2,4,6,8$, and 10 after an i. p. inoculation of BAMC-1 $\left(1 \times 10^{5}\right.$ cells $/$ mouse $)$, unless otherwise stated. The control mice received $0.1 \mathrm{ml}$ saline solution on the same schedule. The number of survivors was monitored for 40 days.

Anti-thymocyte globulin (ATG, Microbiological Associates Inc., Bethesda Md., kindly provided Dr. T. Kataoka) [10] was examined in vivo for influence on the therapeutic effect of OK-432. The i. p. administration of ATG $(0.25 \mathrm{ml} /$ mouse $)$ inhibited the $\mathrm{T}$ cell mitogen response of spleen cells, but not the $B$ cell mitogen response (data not shown). The mitogens used were Concanavalin A (Sigma, St. Louis, Mo., USA), Phytohemagglutinin (Wellcome Reagent Ltd., Beckenham, Kent, England) and Lipopolysaccharide (Difco Lab., Detroit, Mich., USA).

Local Winn-type neutralization assay and adoptive transfer assay. Control mice received $1 \times 10^{5}$ (in $0.1 \mathrm{ml}$ ) viable BAMC- 1 cells by i. p. injection. Experimental mice were inoculated with the same number of cells admixed with $1 \times 10^{7}$ peritoneal exudate cells (PEC). PEC obtained on days 4 to 12 from OK-432-treated tumor-bearing mice were washed once with Eagle MEM (GIBCO, Grand Island, NY) and used either fractionated or unfractionated for the assay. Fractionation was carried out by plastic adherence to adherent (PA) and nonadherent (PNA) cells after incubation for $1 \mathrm{~h}$ at $37^{\circ} \mathrm{C}$. When the Winn assay result was positive, a more critical assay was conducted to examine the antitumor effect of the $P E C$ in vivo by i. $p$. administration of the PEC 1 day after the mice had been i. p. inoculated with $1 \times 10^{5}$ BAMC- 1 cells (adoptive transfer assay).

Cell depletion with antibody and complement. The $\mathrm{PEC}$ obtained from OK-432-treated tumor-bearing mice were collected in a cold MEM medium, washed once with MEM and suspended in a serum-free-RPMI-1640 medium at a concentration of $2 \times 10^{7} \mathrm{cells} / \mathrm{ml}$. Then $1 \mathrm{ml}$ of cell suspension was incubated for $30 \mathrm{~min}$ at $37^{\circ} \mathrm{C}$ with either monoclonal anti-Thy 1.2 (Olac. clone F7D5) at 1/500 dilution or anti-asialo GM1 (Wako Pure Chemical Ind., Tokyo) at $1 / 50-1 / 200$ dilution. Incubation was then continued for another $45 \mathrm{~min}$ at $37^{\circ} \mathrm{C}$ with a low toxic guinea pig complement (Cederlane Laboratories Ltd., Ontario, Canada) at $1 / 10$ dilution. Treated cells were washed twice with MEM and dead cells were counted by trypan blue dye exclusion. Reconstitution for the cytotoxicity assay, however, was made with the original volume of medium.

In vitro cell mediated cytotoxicity assay. Cell mediated cytotoxicity was assayed by a $4 \mathrm{~h}$ chromium release method [20]. Target cells $\left(1 \times 10^{6}\right.$ cell) were incubated with $100 \mu \mathrm{Ci}$
$\mathrm{Na}_{2} \mathrm{CrO}_{4}$ for $1 \mathrm{~h}$ at $37^{\circ} \mathrm{C}$, washed 3 times with $\mathrm{MEM}$ and resuspended in a $10 \%$ fetal bovine serum-RPMI medium at a concentration of $1 \times 10^{5}$ cells $/ \mathrm{ml}$. Target cell suspensions $(100 \mu 1)$ were incubated with equal volumes of $1 \times 10^{7}$ to $2.5 \times 10^{6} \mathrm{cells} / \mathrm{ml}$ of effector cell suspensions and then incubated for $4 \mathrm{~h}$ at $37^{\circ} \mathrm{C}$ in a round-bottomed 96 -well microtiterplate (Nunclon, Nunc, Denmark). Samples of supernatant $(100 \mu 1)$ were then harvested and counted in a gamma counter (Aloka, Auto Well GAMMA System, ARC-500). The percentage of specific cytotoxicity was calculated using the following formula:

$\%$ specific cytotoxicity $=($ Experimental $\mathrm{cpm}-$ Spontaneous cpm) $\div$ (Total incorporated cpm - Spontaneous cpm) $\times 100$

Cold target cell inhibition assay. Isotopically unlabeled (cold) blocking cells were tested for the ability to inhibit the lysis of target tumor cells by OK-432-induced killer cells. BAMC-1, YAC-1, and B16 melanoma cells were used a blocking cells as well as target cells. Samples of $50 \mu \mathrm{l}$ of the cold blockers at the desired concentration were incubated with $50 \mu \mathrm{l}$ of effector cells $\left(5 \times 10^{5}\right.$ cells $)$ in a 96-well microplate for $30 \mathrm{~min}$ at $37^{\circ} \mathrm{C}$ with $\mathrm{B} / \mathrm{E}$ (blocker to effector) ratios of $2: 1,1: 1$, and $0.5: 1$ respectively. Then $100 \mu \mathrm{l}$ of ${ }^{51} \mathrm{Cr}$-labeled target cells were added to the wells at an effector to target cell ratio of $50: 1$. The plates were incubated for an additional $4 \mathrm{~h}$ prior to harvest, as described for the chromiun release assay.

Statistical analysis. The differences in survival rates were evaluated by the method of Cox and Mantel. All determinations of ${ }^{51} \mathrm{Cr}$ release assay were made in triplicate, and the results were evaluated for statistical significance by Student's $t$-test.

\section{Results}

In vivo antitumor effect of $O K-432$ against $B A M C-1$ tumor

After i. p. inoculation with BAMC-1 $\left(1 \times 10^{5}\right.$ cells/mouse $)$, $\mathrm{BALB} / \mathrm{c}$ mice received an i. p. injection of $\mathrm{OK}-432$ at graded doses $(0.2,0.1$, or $0.05 \mathrm{mg} /$ mouse $)$ for 5 consecutive days (once every 2 days) (Fig. 1). All control mice receiving the saline solution died by day 16 . However, $100 \%$ of mice bearing BAMC-1 ascites tumor, were completely cured after an i. p. injection of a $0.1 \mathrm{mg}$ dose of $\mathrm{OK}-432$, and in repeated experiments, more than $80 \%$ and almost $100 \%$ indefinite survival rate was obtained at this dose. Higher $(0.2 \mathrm{mg} / \mathrm{mouse})$ and lower $(0.05 \mathrm{mg} / \mathrm{mouse})$ doses of OK-432 given under the same conditions were less effective than the dose of $0.1 \mathrm{mg} /$ mouse (Fig. 1).

Antitumor effect of $O K-432$ in athymic $B A L B / c$ nu/nu mice and $A T G$-treated euthymic $B A L B / C$ mice

The next experiment was conducted to find the extent of $\mathrm{T}$ cell participation in the antitumor effect of OK-432. When the administration dose and schedule were repeated in athymic nu/nu mice (Fig. 2) and ATG-treated euthymic mice (Fig. 3), although survival was prolonged significantly in both groups, OK-432 did not reveal the same curative effect as was found in the control nu/ + (Fig. 2) and euthymic mice (Fig. 3). Although life-span was lengthened in the treated mice, these two groups of mice eventually died from tumor growth. When OK-432-treated mice received 


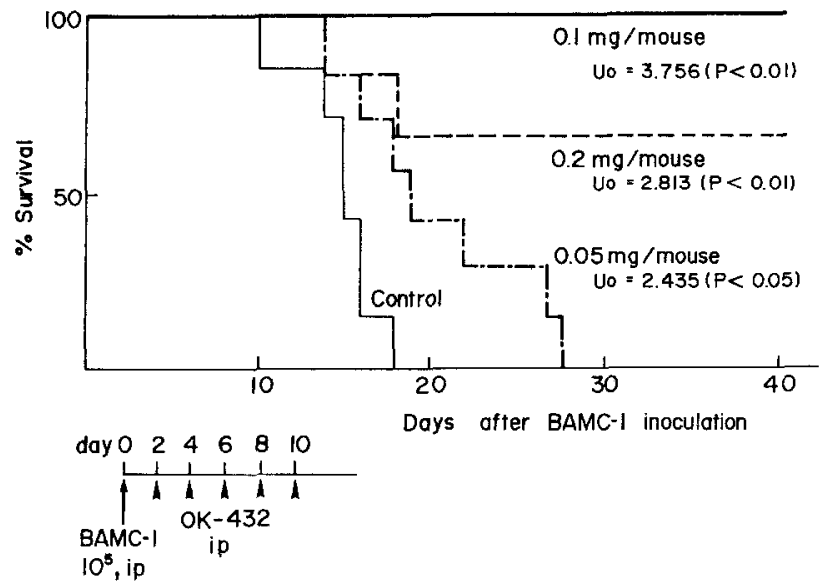

Fig. 1. Dose effect of i.p. OK-432 on the survival of BALB $/ \mathrm{c}$ mice bearing BAMC-1 tumor cells in ascitic form. BAMC-1 cells $\left(1 \times 10^{5}\right)$ were injected i. p. on day 0 to $B A L B / c$ mice. Five consecutive (once every 2 days) i. p. injections of $\mathrm{OK}-432$ in $0.1 \mathrm{ml}$ saline were performed as illustrated by the time schedule (below)
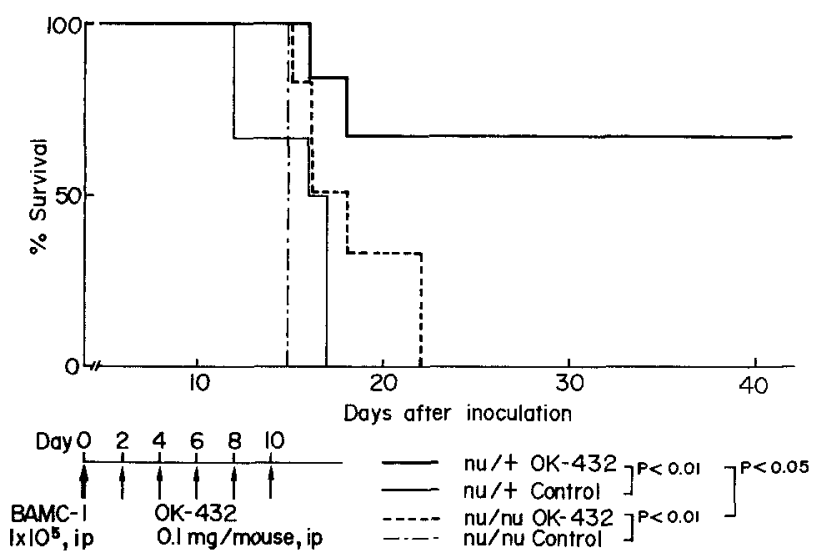

Fig. 2. Antitumor effect of $\mathrm{OK}-432$ on the growth of BAMC-1 in $\mathrm{BALB} / \mathrm{c} \mathrm{nu} / \mathrm{nu}$ and $\mathrm{nu} /+$ mice. Five consecutive i. p. injections of $0.1 \mathrm{mg}$ of OK-432 (as shown below) were used to treat BALB/c $\mathrm{nu} / \mathrm{nu}$ and $\mathrm{nu} /+$ mice receiving BAMC- 1 cells $\left(1 \times 10^{5}\right)$ on day 0

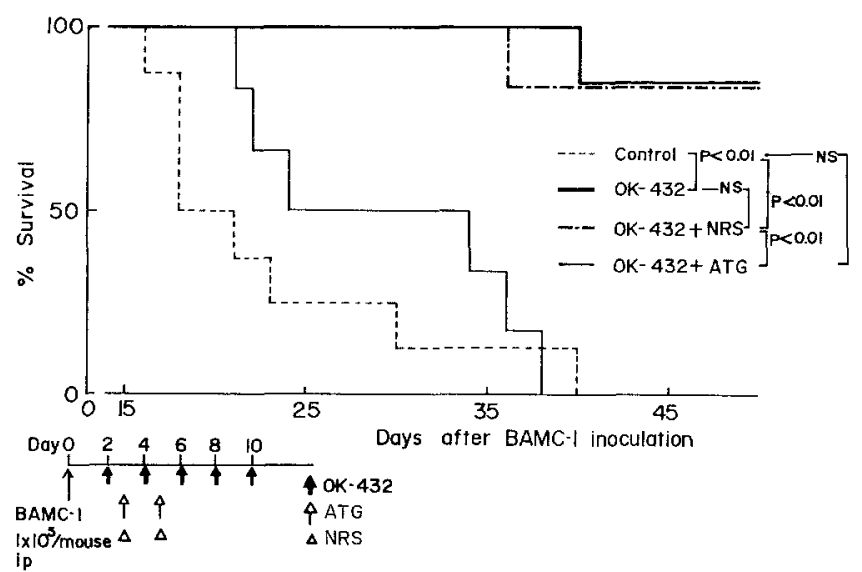

Fig. 3. Effect of in vivo administration of ATG on antitumor effect of OK-432. Experimental details are illustrated below the figure. Other experimental procedures were as for Fig. 1 normal rabbit serum (NRS) instead of ATG (Fig. 3), the therapeutic effect of OK-432 was again evident, resulting in the indefinite survival of $80 \%$ of the mice. These observations strongly suggest that $T$ cell participation is a prerequisite to the complete recovery of $\mathrm{BALB} / \mathrm{c}$ mice from BAMC-1 tumor death.

In vivo tumor neutralization activity of $O K-432-$ induced killer cells

In an attempt to characterize the effector cells in cured euthymic mice, exudate cells, which appeared on day 12 ( 2 days after the last injection of OK-432) in the peritoneal cavity of OK-432-treated tumor-bearing mice, were examined for their in vivo effect, using a local Winn-type neutralization assay. The PEC obtained were separated into PA (75\%) and PNA cells (25\%), and these two fractions, each adjusted to contain $1 \times 10^{7}$ cells, were admixed with BAMC- 1 cells $\left(1 \times 10^{5}\right)$ and injected i. p. into normal BALB/c mice (Fig. 4). All untreated control mice died by day 17 . When the mice received the admixture of tumor cells and unfractionated or non-adherent PEC cells, however, all survived for more than 60 days and the animals experienced a complete tumor regression. The mice given PA cells survived for a longer time than the control, and some actually survived, although the tumors did not regress completely. From these findings, it was considered that tumor associated macrophages were able to inhibit tumor growth, but only for a limited period [20]. The fact that PNA cells were more effective in the Winn assay allowed us to further investigate these cell fractions containing effector cells either in vivo or in vitro.

\section{Therapeutic effect of these tumor associated lymphocytes}

Since these PNA cells appearing in the peritoneal cavity neutralized BAMC-1 cells in vivo, further evaluation of their killing activity was made with an adoptive transfer assay. To do this, unfractionated and nonadherent PEC obtained on day 12 from tumor-bearing mice were i. p.

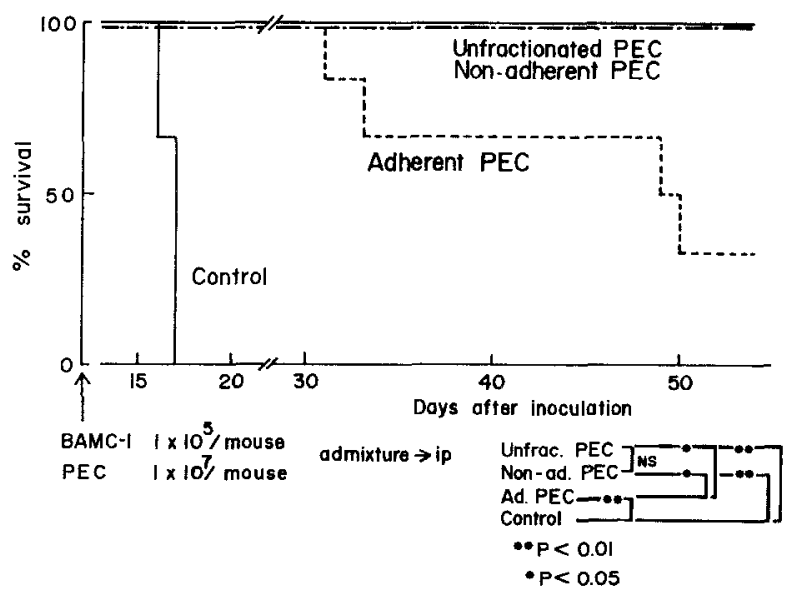

Fig. 4. Antitumor effect of PEC from OK-432-treated tumor-bearing mice using Winn-type neutralization assay. PEC obtained from OK-432-treated tumor-bearing mice on day 12 were separated into adherent and nonadherent cells. These two fractions and unfractionated $\mathrm{PEC}$ adjusted to $1 \times 10^{7}$ cells were mixed with BAMC-1 tumor cells $\left(1 \times 10^{5}\right)$. Admixture was injected i. p. into $\mathrm{BALB} / \mathrm{c}$ mice 


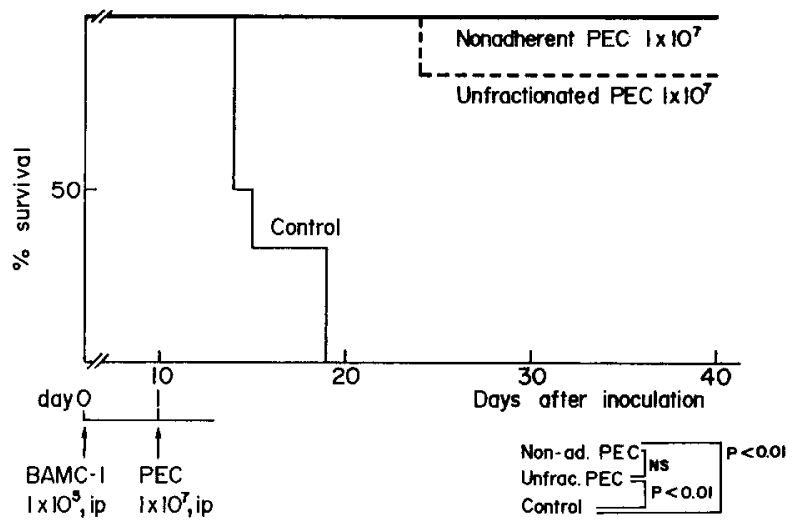

Fig. 5. Antitumor effect after adoptive i. p. transfer of PEC from OK-432-treated tumor-bearing mice. PEC obtained on day 12 from tumor-bearing mice were separated into nonadherent and adherent cells. Nonadherent cells were i. p. transferred 1 day after inoculation of $1 \times 10^{5}$ BAMC- 1 tumor cells

transferred adoptively 1 day after the inoculation of $1 \times 10^{5}$ BAMC-1 tumor cells (Fig. 5). All the mice receiving $1 \times 10^{7}$ nonadherent PEC survived and 5 out of 6 mice survived when they received $1 \times 10^{7}$ unfractionated PEC. Mice receiving less than $3 \times 10^{6}$ nonadherent PEC, however, showed only a slight increase in survival period (data not shown). These results clearly indicated that the in vivo antitumor effect of tumor associated lymphocytes is significant in the sense that their adoptive transfer, even 1 day after tumor implantation, showed a clear-cut therapeutic effect in a cell number dependent manner.

\section{Induction of syngeneic killer cells from tumor-bearing mice}

The next experiment was conducted in vitro to see whether cytotoxic $\mathrm{T}$ cells could be detected against syngeneic BAMC- 1 cells in the peritoneal exudates of BALB $/ \mathrm{c}$ mice on day 12 (Table 1). PEC taken from tumor-bearing untreated mice on day 12 did not show any detectable in vitro cytotoxic activities against BAMC-1, YAC-1, B16, and
EL4 cells. On the other hand, PEC obtained on day 12 from OK-432-treated mice were so highly cytotoxic that they killed not only BAMC-1, B16, and EL4 cells but also NK susceptible YAC-1 cells derived from a different $\mathrm{H}-2$ strain of mice. This syngeneic killer cell activity in PEC appeared from day 8 onwards, but not on days 4 and 6 (data not shown). In Table 1, it is also evident that 3 although not 5 consecutive administrations of OK-432 on days 2,4 , and 6 or on days 2,6 , and 10 were just as effective in inducing the same, or related, killer cells. The result was in concordance with the antitumor effect of 3 consecutive administrations (Table 1).

\section{Characterization of syngeneic killer cells}

Since PEC obtained on day 12 from OK-432-treated mice showed definite cytotoxic activity against BAMC-1 and YAC-1 cells, further characterization of these killer cells was attempted. When PEC obtained on day 12 from five consecutive OK-432-treated mice were incubated in plastic dishes to separate PNA cells from PA cells, cytotoxic activity was enhanced in the former cell population. When anti-Thy 1.2 and anti-asialo GM1 treatment was conducted in order to determine the phenotype of unfractionated killer cells using a complement dependent cytotoxic assay (Table 2), cell killing activity directed against NK-sensitive YAC-1 cells did not decrease to a great extent with antiThy 1.2 treatment, but decreased by almost $100 \%$ with antiasialo GM1 treatment. Cytotoxic activities directed to NKresistant B-16 cells followed almost the same pattern. Syngeneic killer cell activity against BAMC-1 tumor cells, however, was abolished almost completely by either antiThy 1.2 or anti-asialo GM1 treatment. The results indicated that virtually all BAMC-1 directed syngeneic killer cells were Thy $1.2^{+}$and asialo GM1+.

\section{Target cell specificity of syngeneic killer cells}

In an attempt to determine the target cell specificity of these killer cells, several allogeneic and xenogenic NKresistant cell lines were used as target cells. As shown in

Table 1. In vitro cytotoxic activity of PEC obtained after various administration schedules of OK-432 and their antitumor effect

\begin{tabular}{|c|c|c|c|c|c|}
\hline & \multirow[b]{2}{*}{$\mathrm{E} / \mathrm{T}$} & \multirow[b]{2}{*}{ control $^{b}$} & \multicolumn{3}{|c|}{ Days of $\mathrm{OK}-432^{\mathrm{c}}$ administration } \\
\hline & & & $2,4,6,8$, and 10 & $2,4,6$ & $2,6,10$ \\
\hline \multicolumn{6}{|l|}{$\%$ Cytotoxicitya } \\
\hline Target: BAMC-1 & $\begin{array}{r}100: 1 \\
50: 1\end{array}$ & $\begin{array}{r}-0.1 \\
0.3\end{array}$ & $\begin{array}{l}15.5^{\mathrm{d}} \\
11.9^{\mathrm{d}}\end{array}$ & $\begin{array}{l}18.1^{\mathrm{d}} \\
16.4^{\mathrm{d}}\end{array}$ & $\begin{array}{l}14.5^{d} \\
15.0^{d}\end{array}$ \\
\hline YAC-1 & $\begin{array}{r}100: 1 \\
50: 1\end{array}$ & $\begin{array}{r}-0.8 \\
0.2\end{array}$ & $\begin{array}{l}50.4^{\mathrm{d}} \\
42.2^{\mathrm{d}}\end{array}$ & $\begin{array}{l}18.1^{\mathrm{d}} \\
16.4^{\mathrm{d}}\end{array}$ & $\begin{array}{l}14.5^{\mathrm{d}} \\
15.0^{\mathrm{d}}\end{array}$ \\
\hline B16 & $\begin{array}{r}100: 1 \\
50: 1\end{array}$ & $\begin{array}{l}0.5 \\
0.3\end{array}$ & $\begin{array}{l}62.2^{d} \\
40.9^{d}\end{array}$ & $\begin{array}{l}49.4^{\mathrm{d}} \\
34.0^{\mathrm{d}}\end{array}$ & $\begin{array}{l}60.4^{\mathrm{d}} \\
42.9^{\mathrm{d}}\end{array}$ \\
\hline EL4 & $\begin{array}{r}100: 1 \\
50: 1\end{array}$ & $\begin{array}{l}0.9 \\
0.1\end{array}$ & $\begin{array}{l}12.3^{\mathrm{d}} \\
10.5^{\mathrm{d}}\end{array}$ & $\begin{array}{l}\text { NT } \\
\text { NT }\end{array}$ & $\begin{array}{l}\text { NT } \\
\text { NT }\end{array}$ \\
\hline $\begin{array}{l}\text { In vivo antitumor effect } \\
\% \text { survival on day } 40 \\
\text { Tumor free/total }\end{array}$ & & $\begin{array}{l}0 \\
0 / 6\end{array}$ & $\begin{array}{l}100 \\
6 / 6\end{array}$ & $\begin{array}{l}100 \\
5 / 6\end{array}$ & $\begin{array}{l}100 \\
5 / 6\end{array}$ \\
\hline
\end{tabular}

a $4 \mathrm{~h}{ }^{51} \mathrm{Cr}$ release assay result with $\mathrm{PEC}$, obtained 12 days after tumor inoculation

b Tumor(BAMC-1)-bearing control, receiving saline solution on days $2,4,6,8$, and 10

c OK-432 $0.1 \mathrm{mg} / \mathrm{mouse}$, i.p.

d Value significantly higher compared with control $(P<0.01)$ 
Table 2. Phenotypic expressions of unfractionated PEC in tumor-bearing mice induced by OK-432 on day 12

\begin{tabular}{|c|c|c|c|c|c|c|}
\hline \multirow[t]{3}{*}{ Treatment } & \multicolumn{6}{|c|}{$\%$ Cytotoxicity } \\
\hline & \multicolumn{2}{|l|}{ YAC-1 } & \multicolumn{2}{|l|}{ B-16 } & \multicolumn{2}{|c|}{ BAMC-1 } \\
\hline & $100: 1^{b}$ & $50: 1$ & $100: 1$ & $50: 1$ & $100: 1$ & $50: 1$ \\
\hline $\begin{array}{l}\text { None } \\
C^{\prime}\end{array}$ & $\begin{array}{l}60.5 \\
56.0\end{array}$ & $\begin{array}{l}47.2 \\
36.4\end{array}$ & $\begin{array}{l}49.0 \\
44.1\end{array}$ & $\begin{array}{l}35.3 \\
25.7\end{array}$ & $\begin{array}{l}13.5 \\
12.6\end{array}$ & $\begin{array}{l}9.2 \\
9.4\end{array}$ \\
\hline $\begin{aligned} & \text { Anti-AsGM1 }(1 / 50)^{c}+C^{\prime} \\
&(1 / 100)+C^{\prime} \\
&(1 / 200)+C^{\prime}\end{aligned}$ & $\begin{array}{r}4.7^{\mathrm{d}} \\
5.8^{\mathrm{d}} \\
13.3^{\mathrm{d}}\end{array}$ & $\begin{array}{l}1.2^{\mathrm{d}} \\
1.9^{\mathrm{d}} \\
4.5^{\mathrm{d}}\end{array}$ & $\begin{array}{l}1.7^{\mathrm{d}} \\
2.2^{\mathrm{d}} \\
5.9^{\mathrm{d}}\end{array}$ & $\begin{array}{l}0.5^{\mathrm{d}} \\
0.7^{\mathrm{d}} \\
0.9^{\mathrm{d}}\end{array}$ & $\begin{array}{l}1.9^{d} \\
2.5^{d} \\
0\end{array}$ & $\begin{array}{l}2.3^{\mathrm{d}} \\
3.0^{\mathrm{d}} \\
1.4^{\mathrm{d}}\end{array}$ \\
\hline Anti-Thy1 + C' & $35.3^{\mathrm{d}}$ & $19.9^{d}$ & $17.3^{\mathrm{d}}$ & $8.7^{\mathrm{d}}$ & $1.4^{\mathrm{d}}$ & $0.8^{\mathrm{d}}$ \\
\hline
\end{tabular}

a $4 \mathrm{~h}^{51} \mathrm{Cr}$ release assay

b Effector: target

c Dilution of anti-asialo GM1 (anti-AsGM1) serum

d Value significantly lower than that of $C^{\prime}$ treatment $(P<0.005)$

Table 3. Target cell specificity of PEC obtained on day 12 in BAMC-1 inoculated mice receiving 5 consecutive OK-432 injections

\begin{tabular}{|c|c|c|c|c|c|c|}
\hline \multirow[t]{3}{*}{ Target cells } & \multirow[t]{3}{*}{ Origin } & \multirow[t]{3}{*}{$\mathbf{H}-2$} & \multicolumn{4}{|c|}{$\%$ Cytotoxicity } \\
\hline & & & \multicolumn{2}{|c|}{ Control $^{b}$} & \multicolumn{2}{|c|}{$\mathrm{OK}-432^{\mathrm{c}}$} \\
\hline & & & $100: 1$ & $50: 1$ & $100: 1$ & $50: 1$ \\
\hline BAMC-1 & \multirow[t]{3}{*}{$\mathrm{BALB} / \mathrm{c}$} & d sarcoma & 0.6 & 0.4 & $15.8^{\mathrm{d}}$ & $10.4^{\mathrm{d}}$ \\
\hline Meth-A & & d sarcoma & 0.1 & 0.4 & $1.2^{\mathrm{d}}$ & $0.8^{d}$ \\
\hline RL ơ & & d lymphoma & 7.9 & 6.1 & $22.8^{\mathrm{d}}$ & $16.5^{\mathrm{d}}$ \\
\hline EL4 & \multirow[t]{2}{*}{$\mathrm{C} 57 \mathrm{BL} / 6$} & b lymphoma & 2.2 & 3.6 & $12.3^{\mathrm{d}}$ & $10.5^{\mathrm{d}}$ \\
\hline B16 & & melanoma & 1.2 & 0.2 & $34.8^{d}$ & $23.6^{\mathrm{d}}$ \\
\hline P815 & $\mathrm{DBA} / 2$ & d mastocytoma & 0.9 & 0.4 & $8.4^{\mathrm{d}}$ & $5.5^{d}$ \\
\hline YAC-1 & $\mathrm{A} / \mathrm{Sn}$ & $\mathrm{k} / \mathrm{d}$ lymphoma & 9.3 & 3.0 & $51.2^{\mathrm{d}}$ & $47.2^{\mathrm{d}}$ \\
\hline K562 & \multirow{4}{*}{ human } & \multirow{4}{*}{$\begin{array}{l}\text { erythroleukemia } \\
\text { bladder carcinoma } \\
\text { hepatoma } \\
\text { gastric carcinoma }\end{array}$} & NT & NT & 28.8 & 19.6 \\
\hline $\mathrm{T} 24$ & & & NT & $\mathrm{NT}$ & 19.0 & 11.9 \\
\hline PLC & & & NT & $\mathrm{NT}$ & 20.3 & 16.8 \\
\hline KATO 3 & & & NT & NT & 21.3 & 17.0 \\
\hline $\mathrm{BALB} / \mathrm{c}$ & spleen $\mathrm{c}$ & \multirow{2}{*}{$\begin{array}{l}\text { cell } \\
\text { amniotic cell }\end{array}$} & NT & NT & -1.1 & 0.7 \\
\hline FL & human a & & NT & NT & 5.7 & -1.3 \\
\hline
\end{tabular}

"Cytotoxicity against various target cells at an E:T of $100: 1$ and $50: 1$ in a $4 \mathrm{~h}{ }^{51} \mathrm{Cr}$ release assay

b PEC obtained on day 12 in tumor-bearing (BAMC-1) control, receiving saline solution on days 2, 4,6,8, and 10

c PEC obtained on day 12 in tumor-bearing (BAMC-1) mice receiving OK-432 injection on days $2,4,6,8$, and 10

Value significantly higher than that of control $(P<0.01)$

Table 3, PEC from OK-432-treated tumor-bearing mice on day 12 showed cytotoxic activity not only against BAMC-1, B16, YAC-1, and RL $\sigma^{*} 1$ cells but also against NK-resistant mouse EL4 and P815 cells (except for Meth-A cells) and human K-562, T-24, PLC, and KATO 3 cells. However, they did not kill spleen cells of BALB $/ \mathrm{c}$ mice and FL cells. This observation suggests that OK-432 treatment induces killer cell populations to be cytotoxic, not only against BAMC-1 and NK susceptible target cells but also against some NK-resistant mouse and human target cells. The nature of target specificity of these killer cells also coincided with the cytotoxicity of lymphokine-activated killer (LAK) cells as previously reported $[11,13,17]$.

\section{Cold target inhibition test conducted with OK-432-induced killer cells on day 12}

As far as the results of in vitro cytotoxic tests are concerned, definite activity of the same pantropic spectra of target cell specificity was repeatedly obtained when we used PEC from tumor-bearing mice on day 12 after five consecutive treatments. Thus, in order to determine the killer cell population among PEC populations, a cold target inhibition test was conducted (Fig. 6). In Fig. 6A it is evident that the cytotoxicity directed to syngeneic BAMC-1 cells was not adsorbed by the addition of YAC-1 cells, indicating the presence of a population of killer cells specific to BAMC-1, since this killing activity was completely adsorbed when BAMC-1 cells were used for the adsorption. On the other hand, when YAC-1 cells were used for the target cells, although killing activity directed to YAC-1 cells was completely adsorbed by the addition of YAC-1 cells, some activity directed to YAC-1 cells remained after the addition of BAMC-1 cells, in a $B / E$ ratio dependent manner. The adsorbed fraction must have been the killer cells directed to both YAC-1 and BAMC-1, whereas the fraction left after blocking seemed to be active solely against YAC-1 cells. Thus the presence of at least 

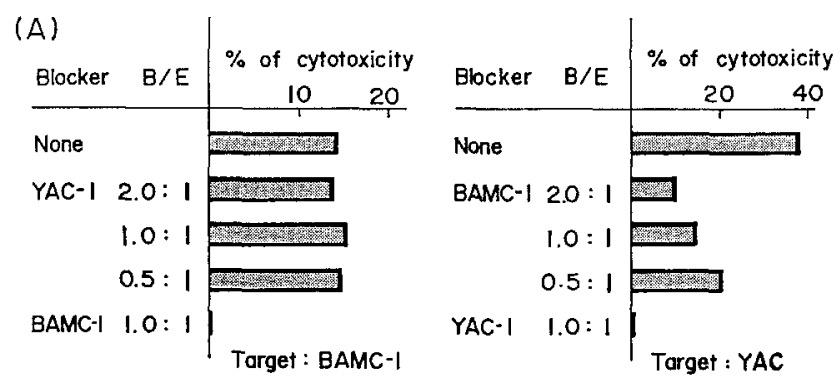

(B)
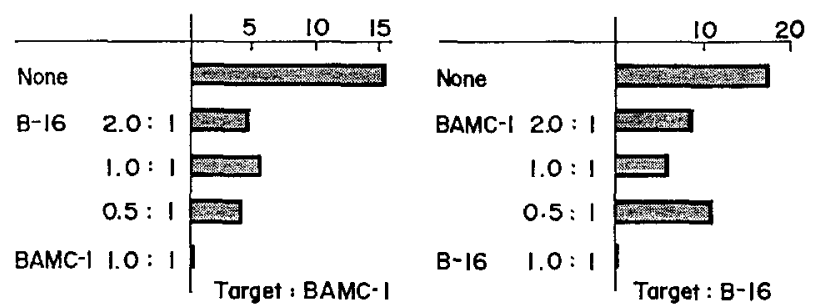

(C)
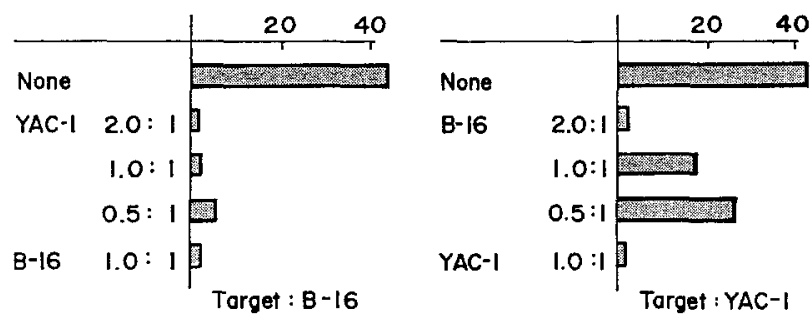

Fig. 6. Cold target inhibition test for OK-432-induced killer cells. PEC obtained on day 12 after five consecutive i. p. injections on days $2,4,6,8$, and 10 were used as effector cells. $\%$ cytotoxicity obtained at different $B / E$ ratios was illustrated when tested in the cold target inhibition assay (effector : target ratio, 50:1)

two different killer groups (BAMC- ${ }^{+}, \mathrm{YAC}_{-} 1^{-}$and BAMC $-1^{+}, \mathrm{YAC}^{-} 1^{+}$) was suggested in this experiment.

In Fig. 6B, when mouse B16 cells (NK-resistant) were used instead of YAC-1 cells (NK-sensitive), the results obtained were essentially concordant with those in Fig. 6A. Although the result does not necessarily mean that killer cells directed to both YAC-1 and BAMC-1 (adsorbed fraction after the blocking with BAMC-1 in Fig. 6A) are the same killer cells directed to both B16 and BAMC-1 (adsorbed fraction after the blocking with BAMC-1 in Fig. 6B), killer cells used in the experiments were Thy 1.2and asialo $\mathrm{GM}^{+}$(as shown in Table 2). In accordance with this consideration, Fig. $6 \mathrm{C}$ shows that when B16 cells were used as the target, cytotoxicity was blocked not only by $\mathrm{B} 16$ but also by YAC-1 cells. When YAC-1 cells were used as the target, B16 cells added at a B/E ratio of $2: 1$, again showed a blocking effect. Thus using a cold inhibition test, the presence of more than two different killer cells in the PEC population was established and will be described elsewhere in more detail.

\section{Discussion}

Although OK-432 was shown in early 1972 to have direct cytotoxic activities [21] against various tumor cells in vitro, the in vivo antitumor effect of OK-432 has only recently been explained by its host mediated mechanisms. In this experiment, the i.p.-i.p. effect of OK-432 against BAMC-1 tumors in BALB/c mice was not dose-dependent, and revealed highest therapeutic activity with a daily dose of $0.1 \mathrm{mg}$ (Fig. 1). This is the dose known so far to be the most active against various mouse tumors originating in different strains of mice $[21,32]$. The presence of an optimal dose suggests that the antitumor effect of OK-432 is due to the activation of host defense mechanisms rather than direct cytotoxic activities.

Uchida et al. reported that local administration of OK432 in cancer patients caused an augmentation of NK activity and autologous tumor cell killing [28, 29]. Effector cells, however, responsible for autologous tumor cell killing in humans were ascribed to NK cells (large granular lymphocytes).

When athymic nu/nu mice or ATG-treated euthymic mice, which lack $\mathrm{T}$ cells or $\mathrm{T}$ cell functions, were used in this experiment, OK-432 administration did not initiate a final recovery in $50 \%$ of the treated mice (Fig. 2 and 3). A complete cure was observed only in hairy euthymic and nu/ + mice (Fig. 1, 2, and 3). These in vivo results suggested that the participation of $T$ cells was essential to reveal the antitumor effect of OK-432 in our system (Fig. 5), even though the initial participation of NK cells cannot be ruled out. Moreover, most of the mice cured in this experiment rejected the same tumor in a specific manner, when rechallenged with BAMC- 1 tumor cells $\left(1 \times 10^{6}\right.$ cells/ mouse s. c.) as late as the 90th day (data not shown). These observations led us to speculate that the development of antitumor immunity against BAMC-1 could be induced by the appearance of some kind of killer T cells, after consecutive i. p. administration of OK-432 (Tables 1, 2, and 3). As described in 1981, i. p. injection of OK-432 resulted in a significant regression of the urinary bladder tumor BC-47, transplanted s. c. into syngeneic ACI/N rats, even though the initial growth of the tumors in OK-432-treated rats was parallel to that of the control rats [7]. In the experiment, the researchers referred to the appearance of cytotoxic PEC after i. p. injection of OK-432. These plastic nonadherent PEC killed not only all of the different rat bladder tumor cells derived from ACI/N rats and hepatoma cells of the same rats, but also Meth-A mouse sarcoma cells. Thus they first established the appearance of relatively pan-spectra killer T cells after i. p. treatment of tumorbearing rats with $\mathrm{OK}-432$ [7].

It has already been reported that i. p. administration of OK-432 in nontumor-bearing mice augments NK activity of PEC [15]. In this experiment, PEC obtained from OK432-treated tumorbearers also demonstrated YAC-1 cell killing activity and syngeneic tumor cell killing activity in vitro (Tables 1,2, and 3 ). The bulk of the population of syngeneic killer cells directed to BAMC-1 (NK-resistant), however, were PNA and their in vitro cell killing activity was abolished by treatment with either anti-Thy 1.2 plus complement or anti-asialo GM1 plus complement (Table 2), suggesting that the bulk of cytotoxic cells were not NK cells. From Table 2, however, it is also apparent that killing activity directed against YAC-1 cells was only partially abolished by anti-Thy 1.2 treatment, suggesting the presence of another heterogenous subpopulation. The presence of more than two populations was actually proved by a cold target inhibition test (Fig. 6), which suggested the presence of at least two different populations. Furthermore, these PEC demonstrated in vitro cytotoxic 
activity, not only against NK susceptible target cells but also against several NK-resistant allogeneic and xenogenic target cells (Table 3 ), suggesting that they might have the same characteristics as LAK cells $[11,13,16,17]$. In our experiments, PEC on day 12 did not kill syngeneic fresh spleen cells and FL cells (Table 3), concordant with the populations of LAK cells. The phenotype of mouse LAK is known to be Thyl.2 positive, and exhibits cytolytic activity against a wide variety of target cells, including NKresistant and NK susceptible tumor cells [11, 17].

A known interesting characteristic of LAK cells is that when they are propagated in vitro in the presence of IL-2, they exhibit strong cytotoxic activities toward a variety of fresh or cultured syngeneic, allogeneic and xenogenic tumor cells, but not toward spleen lymphocytes. Nonspecific broad spectrum killer cells (LAK-like cells) were also obtained from PEC in mice immunized with allogeneic mouse spleen cells [24]. In other reports, LAK-like nonspecific cytolytic effectors were referred to as anomalous killer cells [23], activated lymphocyte killer cells [1] or antisyngeneic tumor killer cells [12], and were all generated in human or mouse allogeneic mixed lymphocyte reactions. Concordant with our results, Kedar's LAK (LCL in his definition) were both Thy $1.2^{+}$and asialo $\mathrm{GM}^{+}[11]$. Although killer cells induced by OK-432 in vivo shared similar characteristics with the in vitro induced LAK cells [11, 17], the fact that the i. p. injection of OK-432 in mice not only induced IFN $\gamma$ but also IL-1 and IL-2 [8] may support the characterization of these cells as a kind of LAK cell. The efficient induction of LAK cells in vivo was first achieved in this experiment by i. p. injection of OK-432.

The whole story may be explained in one of two ways: (1) that OK-432-induced killer cells contain a kind of LAK cell together with specific killer T cells, (2) that all killer cells obtained from OK-432-treated $\mathrm{BALB} / \mathrm{c}$ mice on day 12 might be LAK cells of a heterogeneous population. Whether LAK alone can induce such a long-lasting tumor specific immunity in animals, however, is not well defined. Thus the characterization of $T$ cells in PEC induced by OK-432 still remains for further studies, with the expectation of sequential changes in $T$ cell population (e. g., from LAK cells to specific killer cells) from time to time.

In conclusion, it is apparent that the participation of $T$ cells is essential for a complete BAMC-1 tumor cure in mice, and that syngeneic killer cells are induced by OK432 therapy at the tumor site. Significant in vivo antitumor effects of these nonadherent cells containing Thy $1.2^{+}$and asialo $\mathrm{GMI}^{+}$cells have been demonstrated by a local Winn assay and by adoptive transfer of the cells to tumorbearing animals.

Acknowledgements. Thanks are due to Dr. T. Kataoka for providing the ATG and Dr. S. Suzuki for his helpful discussions and suggestions.

\section{References}

1. Buns GF, Triglia T, Werkmeister IA (1984) In vitro generation of human activated lymphocyte killer cells: Separate precursors, and mode of generation of NK-like cells and "anomalous" killer cells. J Immunol 133: 1656

2. Eberlein TJ, Rosenstein M, Spiess $P$, Wesley R, Rosenberg SA (1982) Adoptive chemoimmunotherapy of a syngeneic murine lymphoma with long-term lymphoid cell lines ex- panded in $\mathrm{T}$ cell growth factor. Cancer Immunol Immunother 13: 50

3. Farrar WL, Johnson HM, Farrar JJ (1981) Regulation of the production of immune interferon and cytotoxic T lymphocytes by interleukin 2. J Immunol 126: 1120

4. Farrar JJ, Benjamin WR, Hilfiker ML, Haward M, Fuller WL, Farrar J (1982) The biochemistry, biology and role of interleukin 2 in the induction of cytotoxic $T$ cell and antibodyforming B cell response. Immunol Rev 63: 129

5. Gorczynski RM (1974) Evidence for in vivo protection against murine sarcoma virus-induced tumors by $\mathrm{T}$ lymphocytes from immune animals. J Immunol 112: 533

6. Herberman RB, Nunn ME, Holden HT, Lavrin DH (1975) Natural cytotoxic reactivity of mouse lymphoid cells against syngeneic and allogeneic tumors II. Characterization of effector cells. Int J Cancer 16: 230

7. Hojo H, Hashimoto $\mathrm{Y}$ (1981) Cytotoxic cells induced in tumor-bearing rats by a streptococcus preparation (OK-432). Gann 72: 692

8. Ichimura O, Suzuki S, Saito M, Sugawara Y, Ishida N (1985) Augmentation of interleukin 1 and interleukin 2 production by $\mathrm{OK}-432$. Int $\mathrm{J}$ Immunopharmacol 7: 263

9. Ishii Y, Yamaoka H, To K, Kikuchi K (1976) Inhibition of tumor growth in vivo by macrophages from rat treated with a Streptococcal preparation, OK-432. Gann 67:115

10. Kataoka T, Oh-hashi F, Sakurai Y, Okabe M, Gomi K (1979) Factors responsible for immune resistance to L1210 murine leukemia in hyperimmune mice. Cancer Immunol Immunother 7: 123

11. Kedar E, Ikejiri BL, Gorelik E, Herberman RB (1982) Natural cell-mediated cytotoxicity in vivo and inhibition of tumor growth in vivo by murine lymphoid cells cultured with $T$ cell growth factor (TCGF). Cancer Immunol Immunother 13: 14

12. Macphail S, Paciucci PA, Stutman O (1984) Phenotypic heterogeneity of antisyngeneic tumor killer cells (ASTK) generated in allogeneic mixed lymphocyte reactions. J Immunol 132: 3205

13. Nishimura T, Hashimoto $Y$ (1984) Induction of nonspecific killer $T$ cells from non-immune mouse spleen cells by culture with interleukin 2. Gann 75: 177

14. Ono T, Kurata S, Wakabayashi K, Sugawara Y, Saito M, Ogawa H (1973) Inhibitory effect of a streptococcal preparation (OK-432) on the nucleic acid synthesis in tumor cells in vitro. Gann 64: 59

15. Oshimi K, Kano S, Takaku F, Okumura K (1980) Augmentation of mouse natural killer cell activity by a Streptococcal preparation, OK-432. J Natl Cancer Inst 65: 1267

16. Rosenberg SA (1984) Adoptive immunotherapy of cancer. Cancer Treat Rep 68: 233

17. Rosenstein M, Yron I, Kaufman Y, Rosenberg SA (1984) Lymphokine-activated killer cells: Lysis of fresh syngeneic natural killer-resistant murine tumor cells by lymphocytes cultured in interleukin 2. Cancer Res 44: 1946

18. Saito M, Ebina T, Koi M, Yamaguchi T, Kawade Y, Ishida N (1982) Induction of interferon in mice spleen cells by OK-432, a preparation of Streptococcus pyogenes. Cell Immunol 68 : 184

19. Saito M, Yamaguchi T, Ebina T, Koi M, Aonuma E, Usami $\mathrm{H}$, Ishida $\mathrm{N}$ (1983) In vitro production of immune interferon (IFN $\gamma$ ) by murine spleen cells when different sensitizing antigens are used in vitro. Cell Immunol 78: 379

20. Saito M, Nanjo M, Aonuma E, Noda T, Nakadate I, Ebina T, Ishida N (1984) Activated macrophages are responsible for the tumor inhibitory effect in mice receiving intravenous injection of OK-432. Int J Cancer 33: 271

21. Sakurai Y, Tsukagoshi S, Satoh H, Akiba T, Suzuki S, Takagaki Y (1972) Tumor-inhibitory effect of a Streptococcal preparation (NSC-B116209). Cancer Chem Rep 56: 36

22. Schultz RM, Paramatheakis JD, Chirigos MA (1978) Functional and morphologic characteristics of interferon treated macrophages. Cell Immunol 35: 84 
23. Seeley JK, Masucci G, Poros A, Klein E, Colub SH (1979) Studies on cytotoxicity generated in human mixed lymphocyte cultures. II. Anti-K562 effectors are distinct from allospecific CTL and can be generated from NK-depleted T cells. J Immunol 123: 1303

24. Sensi M, Orosz CG, Bach FH (1984) Alloantigen-induced cytotoxicity against syngeneic tumor cells: Analysis at the clonal level. J Immunol 132: 3218

25. Shimizu K, Shen FW (1979) Role of different $T$ cell sets in the rejection of syngeneic chemically induced tumors. J Immunol 122: $1162-1165$

26. Torisu M, Katano M, Kimura Y, Itoh H, Takesue M (1983) New approach to management of malignant ascites with a streptococcal preparation, OK-432. I. Improvement of host immunity and prolongation of survival. Surgery $93: 357$

27. Uchida A, Hoshino T (1980) Clinical studies on cell-mediated immunity in patients with malignant disease. Cancer 45: 476

28. Uchida A, Mickshe M (1983) Lysis of fresh human tumor cells by autologous peripheral blood lymphocytes and plural effusion lymphocytes activated by $\mathrm{OK}-432$. J Natl Cancer Inst 71 : 673
29. Uchida A, Mickshe M (1983) Lysis of fresh human tumor cells by autologous large granular lymphocytes from peripheral blood and pleural effusions. Int J Cancer 32: 37

30. Watabe S, Sendo F, Kimura S, Arai S (1984) Activation of cytotoxic polymorphonuclear leukocytes by in vivo administration of a streptococcal preparation, OK-432. J Natl Cancer Inst 72: 1365

31. Watanabe Y, Iwa T (1984) Clinical value of immunotherapy for lung cancer by the streptococcal preparation, OK-432. Cancer 53: 248

32. Yamagishi H, Peris NR, Kahan BD (1980) Streptococcal immunotherapy of a chemical induced murine fibrosarcoma: Effect of dose, route, sham surgery and splenectomy on adjuvant action. Cancer Immunol Immunother 9:63

Received August 13, 1985/Accepted February 7, 1986 